\title{
IMPORTÂNCIA DO PSICÓLOGO NA INTERVENÇÃO DA PSICO-ONCOLOGIA EM MULHERES ACOMETIDAS PELO CÂNCER DE MAMA
}

DOI: $10.22289 / 2446-922 X . V 2 S 1 A 4$

Denise Ribeiro de Azevedo 1

Résia Silva de Morais ${ }^{2}$

Ana Caroline Marafon ${ }^{3}$

\section{INTRODUÇÃO}

O Câncer de mama é um tipo de câncer comum entre as mulheres do mundo e no Brasil, respondendo aproximadamente por $25 \%$, dos casos ao ano. Homens podem ser acometidos pelo câncer de mama, porém é representado por apenas $1 \%$ do total de casos. Segundo o Instituto Nacional do Câncer, o cancro de mama em mulheres, antes dos 35 anos é pouco frequente. Porém, acima desta idade, sua incidência cresce progressivamente, especialmente após os 50 anos. (1)

Vale ressaltar, que há um aumento de óbitos em consequências da doença, e apesar da existência de recursos da ciência e dos avanços tecnológicos, a situação tem se evidenciado como um problema não só social, mas também de Saúde Pública.

O psicólogo é um dos profissionais da saúde, responsável em auxiliar o paciente no enfrentamento da doença, no alivio da dor, do medo e de sentimentos relacionados ao futuro.

Diante do exposto, o objetivo do estudo foi de discutir a importância do psicólogo no tratamento oncológico em mulheres acometidas pelo cancro. Foram destacados alguns conceitos, tais como: a Psicologia da Saúde, Psicologia Hospitalar, Psico-oncologia e câncer.

\section{MÉTODOS}

\footnotetext{
${ }^{1}$ Graduanda em Psicologia pela Faculdade Patos de Minas (FPM).

${ }^{2}$ Mestre em Psicologia da Saúde/Processos cognitivos pela Universidade Federal de Uberlândia (UFU). Docente do Departamento de Graduação em Psicologia da Faculdade Patos de Minas (FPM). E-mail de contato: resiamorais@gmail.com

${ }^{3}$ Mestre em Promoção de Saúde pela Universidade de Franca (UNIFRAN). Docente do Departamento de Graduação em Psicologia da Faculdade Patos de Minas (FPM). Email de contato: anacarolmarafon@hotmail.com
} 
O estudo é de natureza bibliográfica, resultante do trabalho de conclusão de curso.

O levantamento do material deu-se com base nos descritores: oncologia - mama - psicologia, no período compreendido de 2005 a 2015, publicados em português, disponíveis na base de dados da: Scielo, Pepsic e Bireme, selecionados a partir dos protocolos clínicos e as diretrizes terapêuticas em oncologia; considerando os dados do Instituto Nacional do Câncer.

\section{RESULTADOS E DISCUSSÃO:}

A Psicologia no campo da saúde constitui em configuração de compreender o adoecimento e as estratégias que o homem busca para manter-se saudável. (2) Uma questão importante está na diferenciação entre Psicologia da Saúde e Psicologia hospitalar. A Psicologia da Saúde, busca uma visão macro da Saúde, com temas pertinentes à saúde pública, epidemiologia e política. Já a Psicologia Hospitalar é uma área inserida na Psicologia da Saúde, enfatiza a prática do psicólogo dentro do hospital. Apesar da Psicologia da Saúde e a Psicologia Hospitalar serem duas áreas distintas, são entrelaçadas. ${ }^{(3)}$

Deste modo, a psico-oncologia está envolvida com os fatores psicológicos e comportamentais que contribuem no processo de adoecimento e cura, e também as possíveis intervenções. Sendo assim, aprofundou em técnicas de potencialização dos tratamentos médicos, para instruir cada paciente a utilizar recursos mentais de maneira focal e alcançar resultados positivos com os medicamentos. Além de propiciar estratégias de autocuidado e fortalecimento a favor da saúde física e mental dos pacientes, familiares e equipe profissional. (4)

O câncer é cercado de dogmas e estigmas e as pessoas se interagem e agem aos dogmas que as cercam. Os tratamentos como a quimioterapia, radioterapia e mastectomia, deixam o paciente abalado. Deparado com o corpo fora da sua normalidade, o psicólogo intervém desconstruindo o sistema de crenças que o impede de acessar os recursos internos e externos disponíveis para o enfrentamento de uma crise. Prepara o paciente para a abertura de sentimentos e permite a fala dos mesmos, ajustando-os. Através dos dados analisados e levantados identificou-se que a postura do psicólogo é contribuir para inserção da paciente à sociedade, resgate emocional sujeito, uma vez que, o câncer impõe o limite da possibilidade do tempo de vida, resultante a morte.

Por submeter à mastectomia, é comum surgir mudanças no âmbito físico e psicológico, principalmente pelos pensamentos de desesperança, alterações no âmbito familiar e no cotidiano da mulher. ${ }^{(5)}$ Essa perda induz a mulher a se perceber de maneira negativa em relação a sua autoimagem, prejudicando as relações afetivas e sexuais. ${ }^{(6)}$

Portanto, é sabido que o medo é uma reação natural do sujeito quando está diante de algo que não conhece, e o psicólogo deve entender sua individualidade perante a doença, 

seu histórico familiar e seu contexto cultural resgatando a coragem existente, mas adormecida antes do cancro.

\section{CONSIDERAÇÕES}

Foi demonstrado através do estudo, que as mulheres acometidas pelo carcinoma e que são submetidas à mastectomia, manifestam mudanças de origens físicas e psicológicas, principalmente em relação à imagem corporal.

Em decorrência de tais circunstâncias, é necessário o acompanhamento psicológico a partir da confirmação do diagnóstico. O terapeuta deverá desenvolver no paciente uma postura ativa e participativa durante o tratamento, ao enfrentar a perda e as alterações físicas do corpo.

Além do mais, o psicólogo oncológico, atua auxiliando os pacientes em alcançar resultados satisfatórios com o tratamento medicamentoso, tecnológico e cirúrgico.

Portanto conclui-se que a figura do psicólogo no contexto hospitalar é tão fundamental quanto às outras formas de acompanhamento, pois o terapeuta ameniza o sofrimento, a angústia e a solidão nesse momento de grave desgaste emocional. Muitas vezes é necessário interpretar através da escuta e do acolhimento, as emoções afloradas do paciente, da família e dos membros da equipe, dando suporte emocional a todos, e por fim, permitir o sucesso do tratamento ou a preparação para a morte como parte da vida.

\section{REFERÊNCIAS}

1. Instituto Nacional do Câncer. Ações e Programas no Brasil- Controle do câncer de mama. INCA; 2015.

2. Capitão CG, Scortegagna SA, Baptista MN. A importância da avaliação psicológica na saúde. Rev Aval Psicol. [periódico na internet]. 2005 [citado 2016 mar.21]:4(1):75-74. Disponível em: pepsic.bvsalud.org/pdf/avp/v4n1/v4n1a09.pdf

3. Teixeira EB, Pires EF. Psico-oncologia: proposta de trabalho de apoio psicossocial aos pacientes com câncer. Rev Saúde. 2010;4(1):40-52.

4. Veit MT, Carvalho VA. Psico-oncologia:um novo olhar para o câncer. Mundo Saúde. 2010. $34(4) ; 526-530$. 
5. Mezzomo NR, Abaid JL. O câncer de mama na percepção de mulheres mastectomizadas. RevPsicolPesq [periódico na internet]. 2012 [citado 2015 out.13].6(1);40-9.

6. Costa AM, Pereira R, Vasconcelos TB, Farias MS, Praça LR, Bastos VP. Mulheres e a mastectomia: revisão literária. RevAtencão Saúde. 2015; 13(44):58-63. 